\title{
Access to pharmaceutical products in six European countries - analysis of different pharmaceutical distribution systems
}

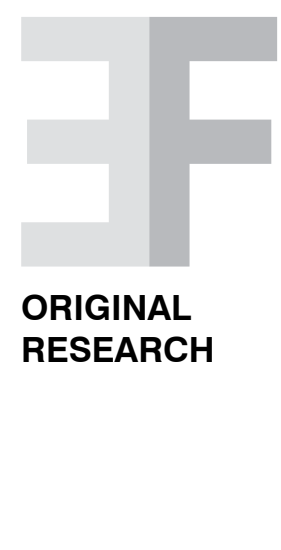

\author{
Evelyn Walter ${ }^{1}$, Aline Dragosits ${ }^{1}$, Monira Said ${ }^{1}$ \\ Institute for Pharmaeconomic Research, Vienna, Austria
}

\begin{abstract}
OBJECTIVES: The aim of the study was to draw a comprehensive picture of the pharmaceutical wholesale sector, outlining its socio-economic importance compared to different distribution systems such as short-line wholesaling, direct sales from manufacturers, Reduced Wholesale Arrangements (RWA) and Direct to Pharmacy (DTP) arrangements. Its role is considered from an economic, effectiveness and, most importantly, a public health viewpoint with qualitative and quantitative methods, focusing on France, Germany, Italy, the Netherlands, Spain and the UK.

METHODS: First, data has been sourced from annual GIRP and IMS-Health statistics; second, a systematic literature research verified the empirical findings; third, an online-questionnaire was directed to pharmacies. Further data have been sourced from a questionnaire, addressing GIRP-full-member associations and wholesale companies (return rate $86 \%$ ). RESULTS: On a weighted average, pharmaceutical full-line wholesalers in the observed countries alone pre-finance $€ 10.2$ bn over a period of 41 days the entire medicine-market and secure the cash-flow of the social-insurers (Germany: $€ 2.60$ bn for 38 days; Italy: $€ 2.27$ bn for 68 days; the UK: $€ 1.48$ bn for 36 days; France: $€ 1.28$ bn for 22 days; Spain: $€ 969.76$ $\mathrm{m}$ for 27 days; the Netherlands: $€ 399.09 \mathrm{~m}$ for 30 days on average). On average, pharmaceutical full-line wholesalers are bundling products of 18.28 manufacturers per delivery. The process costs would increase by $€ 164,922.43$ to $€ 171,510.06$ per year, if there were no pharmaceutical full-line wholesalers. These additional costs would have to be paid by manufacturers, pharmacies and finally by patients. Regarding the satisfaction with different distribution models, the results of the online-questionnaire show that pharmacists in the observed countries are very satisfied with the distribution through their pharmaceutical full-line wholesalers.

CONCLUSIONS: The study showed that pharmaceutical full-line wholesalers have an important and unique position in the pharmaceutical supply chain. Special functions like the pre-financing of the entire medicinal product market, or the guarantee of the continuous supply of all medicinal products verify these findings.
\end{abstract}

Keywords

Pharmaceutical distribution; Europe; Full-line wholesaler; Short-line wholesaler; Direct sales; DTP; RWA

\section{INTRODUCTION}

The distribution and supply of medicinal products have a direct impact on the quality of the health care system, because they are responsible for the immediate availability of medicinal products. In most European countries, the majority of medicinal products are distributed through the following distribution pathway: manufacturer $\rightarrow$ (prewholesaler) $\rightarrow$ pharmaceutical full-line wholesaler $\rightarrow$ retail pharmacy $\rightarrow$ patient. Pharmaceutical full-line wholesalers supply the majority $(74 \%)$ of medicinal products sold in Europe [1]. Moreover, pharmaceutical full-line wholesalers distribute medicinal products to retail pharmacies $(93 \%)$, hospital pharma- cies $(4 \%)$, dispensing doctors $(2 \%)$, drugstores, and others (1\%) [2].

Although pharmaceutical full-line wholesalers still occupy a central position in the supply chain, major transformations took place in the European pharmaceutical distribution landscape, which led to the rise of new distribution models in the recent years. On the one hand the turnover of direct sales from manufacturers has increased in some countries, and on the other hand - like in the UK - new distribution models like Direct to Pharmacy (DTP) or Reduced Wholesale Arrangements (RWA) have emerged (GIRP oral information 2011, [3]). These structural changes lead to the fact that no pharmaceutical wholesaler in the UK carries the full range of medici-
Corresponding author Evelyn Walter PhD, Institute for Pharmaeconomic Research, Wolfengasse 4/7, Vienna, 1010, Austria Phone: +43151320 07 Fax: +431513200715 e.walter@ipf-ac.at

\section{Disclosure}

Institute for Pharmaeconomic Research (IPF), Vienna, Austria received funding from GIRP (The European Association of Pharmaceutical Full-line Wholesalers

- Groupement International de la Répartition Pharmaceutique) for conducting the study. Evelyn Walter, Aline Dragosits and Monira Said are employees of IPF. All authors contributed equally to this work 
nal products [4]. After the introduction of the first Direct to Pharmacy arrangement by Pfizer in 2007, experts were concerned about limited supplies to pharmacies, reduced service levels (pharmacies to patients), reduced margins but increased distribution costs [5]. Considering the recent transformations, this study aimed at analyzing the structures, characteristics, efficiency and performance of the different distribution systems, such as pharmaceutical full-line wholesaling, pharmaceutical short-line wholesaling, direct sales from manufacturers, RWA and DTP arrangements. To reach this aim and in order to compare the different distribution systems, core indicators such as market share, product range, pre-financing, satisfaction with the distribution systems in use, delivery time as well as the impact on process costs, if there were no pharmaceutical full-line wholesalers, were calculated and respectively collected.

The analysis particularly focused on the role of pharmaceutical full-line wholesalers as the main pharmaceutical suppliers. This position is being considered from an economic, effectiveness and a public health viewpoint [4].

\section{MATERIALS AND METHODS}

To analyze the impact of different pharmaceutical distribution systems on the access to pharmaceutical products, primary and secondary sources were used to obtain the necessary data.

\section{Study design}

The study considers the above-described core indicators of the six biggest European pharmaceutical markets: France, Germany, Italy, the Netherlands, Spain and the United Kingdom (UK).

To gain up-to-date information, the following study design was applied:

- Statistical and qualitative data were provided by the European Association of Pharmaceutical Full-line Wholesalers (GIRP). Against this context GIRP's annual report, statistical information gathered through GIRP's member association as well as IMS Health data were used in this study.

- To verify the data and to gain further information about the difference in the time effort for ordering medicinal products, a systematic literature research was conducted.

- An online questionnaire was developed, addressing pharmacists of five out of the six European major markets (France, Germany, the Netherlands, Spain and the UK; due to the lack of response from Italian pharmacists, this country has been excluded from analysis).

- To obtain detailed information about the core indicators pre-financing and product range of pharmaceutical full-line wholesalers, an additional questionnaire - addressing GIRP full-member associations and direct-member companies - was de-

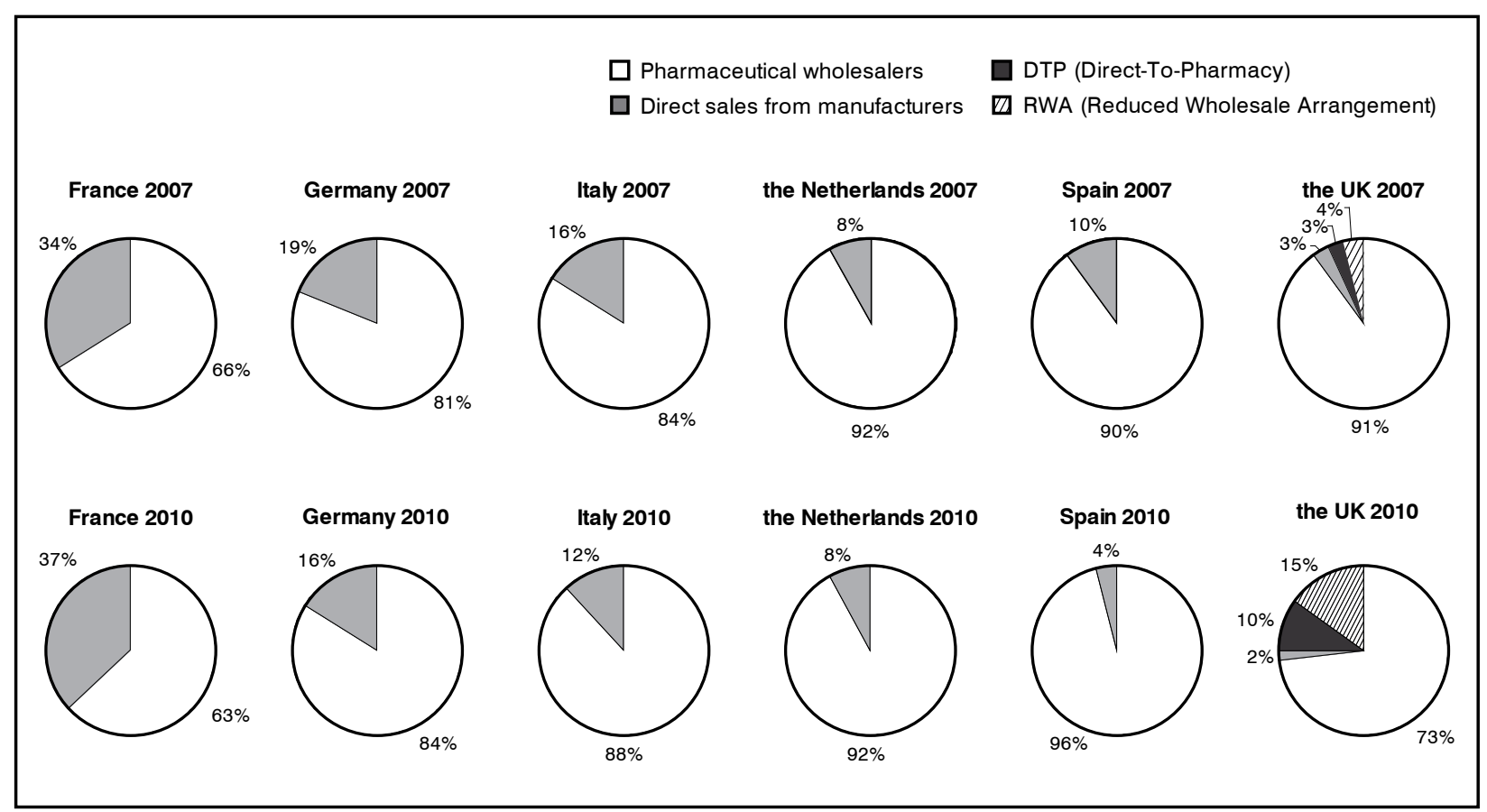

Figure 1. Turnover (units) by distribution channel - retail market France, Germany, Italy, the Netherlands, Spain, the UK, 2011 [Source: Authors' own calculation based on BG Pharma written information 2011, GIRP data 2007-2010, IMS health 2007-2011, CSRP written information 2011] 
signed. This information was sent electronically. Over a period of two months (May to June 2011) a return rate of $86 \%$ was achieved.

\section{Market share}

The turnover expressed in volumes represents the market share of wholesalers (fullline and short-line), direct sales from manufacturers, DTP and RWA. The figures are based on data from IMS health and illustrate the retail market (Figure 1).

\section{Pre-financing}

The calculation of the pre-financing is based on the Net Working Capital approach. According to this, the Net Working Capital Days are calculated as the sum of Days Sales Outstanding (DSO - capital commitment from accounts receivable) and Days Inventory Outstanding (DIO - capital commitment from stock) minus Days Payable Outstanding (DPO - pre-financing from manufacturers) [6].

In the course of the wholesalers' survey core indicators like inventory turnover (DIO), DSO and DPO were collected to calculate the amount of pre-financing.

\section{Pharmacists' questionnaire}

The aim of the online questionnaire was to evaluate the pharmacists' satisfaction with the different pharmaceutical distribution systems and to detect potential concerns associated with these systems. Furthermore, additional core indicators such as delivery time of the different distribution systems as well as the number of manufacturers whose products are pooled in one order from one pharmaceutical full-line wholesaler were collected. In the period between March and October 2011, 473 pharmacists (66 in France, 100 in Germany, 89 in the Netherlands, 124 in Spain and 94 in the UK) answered the questionnaire.

The results illustrate a trend and were analyzed with the software PASW (Predictive Analysis Software).

\section{Process costs}

Process costs were calculated based on the findings of a study conducted by the Institut für Pharmakoökonomie und Arzneimittellogistik (IPAM) (for detailed information please see original source) [7].

The findings of the study showed that all necessary process steps are carried out by pharmacy assistants. Therefore, national gross salaries per minute for pharmacy assistants were calculated and multiplied with the recorded time effort caused per order from pharmaceutical full-line wholesalers, respec- tively from direct sales from manufacturers. The salary information was obtained from official statistical sources (Istat oral information, 2001) [8-12].

The calculations are based on the assumptions of the Institut für Handelsforschung (IfH) [13].

To compare the impact on process costs per pharmacy and year of pharmaceutical fullline wholesalers and direct sales from manufacturers, the calculation is based on the following data and assumptions:

- The delivery frequency per day derived from the records of GIRP's national association members. The calculation of the deliveries per year is based on the assumption that pharmacies are supplied six times per week -52 weeks per year - by their pharmaceutical full-line wholesalers.

- Pharmaceutical full-line wholesalers pool numerous medicinal products from different manufacturers per order. Data from the pharmacists' questionnaires were used to gain this information for each market. The process costs of a delivery from one manufacturer were multiplied by the number of different manufacturers pooled per wholesale order to compensate the costs and to compare it with the costs per order from pharmaceutical fullline wholesalers. To calculate the impact on the process costs of the direct sales from manufacturers, the process costs were multiplied amounting to $25 \%, 50 \%$ or $100 \%$ of wholesale deliveries per year.

\section{RESULTS}

The key European markets in our study are multichannel systems with full-line wholesaling, short-line wholesaling and direct sales [14]. However, in the recent years, new distribution models have emerged, like DTP and RWA in the UK, where pharmaceutical full-line wholesalers are no longer operating as a one stop shop [15]. In the DTP distribution model pharmaceutical manufacturers deliver their medicinal products directly to the pharmacies through one or more logistic service providers. So far, only pharmaceutical full-line wholesalers operate as logistic service providers, whereas in the RWA, pharmaceutical manufacturers use only a small number of selected wholesalers to distribute medicinal products [15].

Due to the fact that neither European nor national legislation offers clear definitions or classifications of the operators in the distribution chain, several national authorities grant a high number of distribution licenses resulting 
in the fact that a diverse range of different operators are active in the market, even in markets where their activities are theoretically prohibited, which is the case in France and Spain. Due to a lack of control, it is possible that such distributors are still operating in the market [16]. Table I gives an overview of key features of the pharmaceutical distribution systems in the key markets observed.

In the observed six countries, 176 wholesale companies (21 of them on a national basis) generated an enormous turnover of $€ 91 \mathrm{bn}$. These companies are holding 730 operating sites, guaranteeing the continuous supply of 104,300 dispensing points for the 332 million citizens. Furthermore, pharmaceutical fullline wholesalers are holding 52,773 items on stock on average. Additionally, pharmaceutical full-line wholesalers in the six observed countries guarantee a delivery within 2.66 hours, 15.88 times per week on average $[2,17]$.

\section{Market share}

Due to the growing importance of alternative distribution systems as well as the increase of direct sales in many other countries and new regulations curbing pharmaceutical expenditure, the turnover of the wholesale sector has been negatively affected by reduced margins following health care reforms and/or austerity measures. Furthermore, the increasing number of patents expiring has led to a growing number of cheaper products [15].

The change in the pharmaceutical portfolios is another important factor, influencing the market growth rate of the pharmaceutical wholesale model versus the direct sales model. According to the public service function, pharmaceutical full-line wholesalers have to handle all medicinal products, whereas pharmaceutical short-liners and direct sales distributors have the option to predominantly distribute specialty, high volume and high margin products (“cherry picking") $[15,18]$.

\section{Pre-financing}

Pharmaceutical full-line wholesalers are the only ones who offer a pre-financing function toward manufacturers and pharmacies. By purchasing medicinal products from manufacturers, pharmaceutical full-line wholesalers acquire the ownership over these products. This ownership is then passed on to pharmacies when medicinal products are delivered. Pharmaceutical full-line wholesalers also undertake a significant contribution to hedge the cash flow in the social security system, as pharmacies frequently delay (often after reimbursement from the Statutory Health Insurance (SHI)) the payments. Moreover, in the context of warehousing, the coverage of incurred capital commitment and risks, such as spoilage, breakage and loss is guaranteed [13].

Nearly the entire medicinal product market is pre-financed by pharmaceutical wholesalers and can be expressed in terms of working capital. The calculation of the pre-financing was based on a national pharmaceutical fullline wholesale basis, as they can claim to be representative for all wholesalers in the markets observed. On a weighted average, pharmaceutical full-line wholesaler in France,

\begin{tabular}{|c|c|c|c|c|c|c|}
\hline & France & Germany & Italy & The Netherlands & Spain & The UK \\
\hline Type of distribution & Multichannel & Multichannel & Multichannel & Multichannel & Multichannel & Multichannel \\
\hline Distribution through & $\begin{array}{l}\text { Full-line ws } \\
\text { Short-line ws* } \\
\text { Direct sales }\end{array}$ & $\begin{array}{l}\text { Full-line ws } \\
\text { Short-line ws } \\
\text { Direct sales }\end{array}$ & $\begin{array}{l}\text { Full-line ws } \\
\text { Direct sales }\end{array}$ & $\begin{array}{l}\text { Full-line ws } \\
\text { Short-line ws } \\
\text { Direct sales }\end{array}$ & $\begin{array}{l}\text { Full-line ws } \\
\text { Short-line ws* } \\
\text { Direct sales }\end{array}$ & $\begin{array}{c}\text { Full-line ws** } \\
\text { Short-line ws } \\
\text { Direct sales } \\
\text { DTP, RWA }\end{array}$ \\
\hline Wholesale licenses & 25 & 4,000 & 650 & 300 & 300 & 1,675 \\
\hline $\begin{array}{l}\text { Regional full-line } \\
\text { wholesalers }\end{array}$ & 3 & 8 & 83 & 0 & 55 & 6 \\
\hline $\begin{array}{l}\text { National full-line } \\
\text { wholesalers }\end{array}$ & 3 & 5 & 2 & 5 & 3 & 3 \\
\hline National PSOs & Yes & Yes & Yes & No & Yes & No \\
\hline $\begin{array}{l}\text { Wholesalers deliver to } \\
\text { hospital }\end{array}$ & No & No & No & Yes & Yes & Yes \\
\hline$\varnothing$ deliveries/day & 2 & 3.3 & 3 & 1 & 3 & 2 \\
\hline
\end{tabular}

Table I. Overview of key features of the pharmaceutical distribution systems in France, Germany, Italy, the Netherlands, Spain, the UK, 2011 [4]

* Theoretically, there are no pharmaceutical short-line wholesalers in France and Spain because their activities are prohibited in these countries. Due to a lack of clear definitions in national legislations a wide and diverse range of different operators is active in the supply chain

** Currently there are no wholesalers in the UK carrying the full range of products

DTP = Direct to Pharmacy; PSO = Public Service Obligation; RWA = Reduced Wholesale Arrangements; ws = wholesaler 


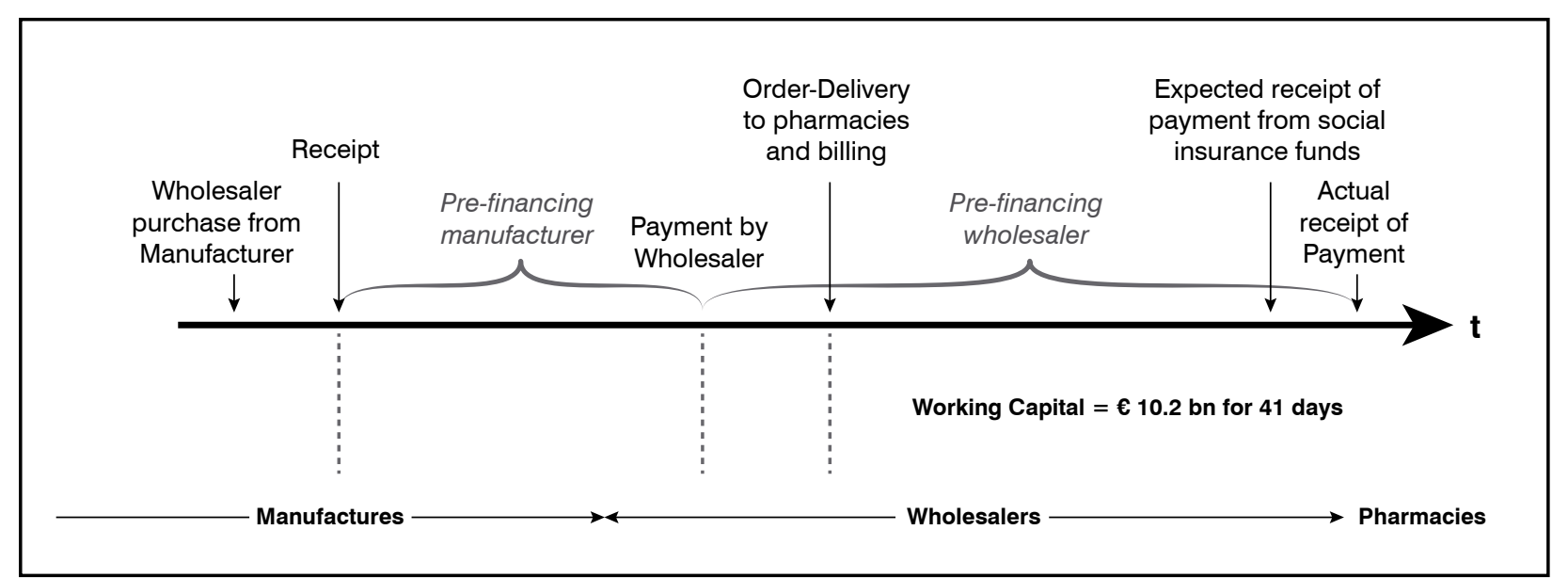

Figure 2. Pre-financing in bn € in France, Germany, Italy, the Netherlands, Spain, the UK, 2010 [4]

Germany, Italy, the Netherlands, Spain and the UK alone pre-finance on average $€ 10.2$ bn over a period of 41 days. In total, this sum is pre-financed approximately nine times per year (Figure 2).

The country specific results revealed that in Germany, pharmaceutical wholesalers pre-finance $€ 2.60$ bn for 38 days, in Italy $€ 2.27$ bn for 68 days, in the UK $€ 1.48$ bn for 36 days, in France $€ 1.28$ bn for 22 days, in Spain $€$ $969.76 \mathrm{~m}$ for 27 days and in the Netherlands $€ 399.09 \mathrm{~m}$ for 30 days on average (Figure 3 ).

\section{Pharmacists' satisfaction}

With regard to the distribution system, the results revealed that in most of the observed countries, more than three quarters of the respondent pharmacists were satisfied with the distribution through pharmaceutical full-line wholesalers. The satisfaction of the participating pharmacists with this type of distribution system ranged from $99 \%$ in Spain to $72 \%$ in the UK. With regard to the delivery time offered by pharmaceutical full-line wholesalers, the satisfaction ranged from $97 \%$ in Spain to $76 \%$ in UK. With the distribution through the pharmaceutical short-line wholesalers, more than half $(63 \%)$ of the German pharmacists were satisfied, whereas only $50 \%$ of the Dutch participants showed satisfaction. Regarding the delivery time offered by pharmaceutical short-line wholesalers, a slight majority $(56 \%)$ of the German pharmacists were satisfied, while less than half (44\%) of the respondents in the Netherlands reported their satisfaction with the delivery time of pharmaceutical short-line wholesalers as "neutral"; $39 \%$ were satisfied, and 17\% showed dissatisfaction.

The results of the satisfaction with the distribution through direct sales from manufactures revealed that less than half of the respondents in four out of the five countries observed were satisfied. The satisfaction ranged from $58 \%$ in Spain to $12 \%$ in UK. The majority $(80 \%)$ of the pharmacists in the UK were unsatisfied with this kind of distribution system. The satisfaction with the delivery time ranged from $41 \%$ in Germany and the Netherlands to $15 \%$ in the UK; whereas the dissatisfaction ranged from $76 \%$ in UK to $9 \%$ in the Netherlands.

According to the questionnaire findings, the respondent pharmacists were concerned about the ability to provide service to patients (Germany, UK, Spain) as well as increasing stock and order effort (Germany, UK) when ordering their medicinal products from direct sales from manufacturer. Regarding the satisfaction with the distribution through DTP and the delivery time offered, the majority of the pharmacists in the UK were unsatisfied. More than half $(59 \%)$ of the respondent pharmacists in UK were not satisfied with the delivery time through RWA (Table II).

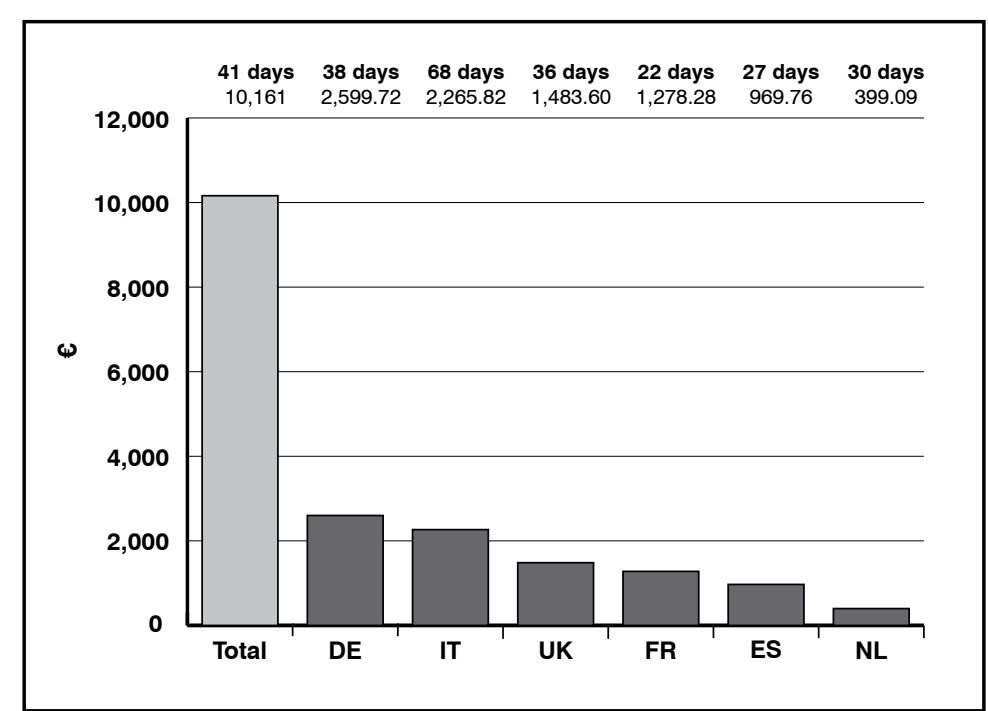

Figure 3. Pre-financing in million $€$ in France (FR), Germany (DE), Italy (IT), the Netherlands (NL), Spain (ES), the UK, 2010 [4] 


\begin{tabular}{|c|c|c|c|c|c|c|}
\hline & \multicolumn{3}{|c|}{ Satisfaction with the distribution system (\%) } & \multicolumn{3}{|c|}{ Satisfaction with the delivery time (\%) } \\
\hline & Satisfied & Neutral & Unsatisfied & Satisfied & Neutral & Unsatisfied \\
\hline \multicolumn{7}{|c|}{ Pharmaceutical full-line wholesalers } \\
\hline France & 90.90 & 6.10 & 3.00 & 95.50 & 4.50 & - \\
\hline Germany & 78.70 & 14.60 & 6.70 & 92.10 & 7.90 & - \\
\hline The Netherlands & 75.30 & 20.20 & 4.50 & 86.50 & 12.40 & 1.10 \\
\hline Spain & 99.20 & 0.80 & - & 96.70 & 1.60 & 1.60 \\
\hline The UK & 71.86 & 12.67 & 15.52 & 75.87 & 12.64 & 11.54 \\
\hline \multicolumn{7}{|c|}{ Pharmaceutical short-line wholesalers } \\
\hline Germany & 62.50 & 37.50 & - & 56.30 & 25.00 & 18.80 \\
\hline The Netherlands & 50.00 & 33.30 & 16.70 & 38.90 & 44.40 & 16.70 \\
\hline \multicolumn{7}{|c|}{ Direct sales from manufacturers } \\
\hline France & 51.80 & 42.90 & 5.40 & 32.10 & 55.40 & 12.50 \\
\hline Germany & 49.20 & 39.00 & 11.90 & 40.70 & 47.50 & 11.90 \\
\hline The Netherlands & 50.00 & 36.40 & 13.60 & 40.90 & 50.00 & 9.10 \\
\hline Spain & 57.70 & 41.00 & 1.30 & 21.80 & 43.60 & 34.60 \\
\hline The UK & 11.90 & 8.50 & 79.70 & 15.30 & 8.50 & 76.30 \\
\hline \multicolumn{7}{|c|}{ DTP (Direct to Pharmacy) } \\
\hline The UK & 8.00 & 2.30 & 89.70 & 9.20 & 14.90 & 75.90 \\
\hline \multicolumn{7}{|c|}{ RWA (Reduced Wholesale Arrangements) } \\
\hline The UK & 6.20 & 3.10 & 90.80 & 13.80 & 27.70 & 58.50 \\
\hline
\end{tabular}

Table II. Satisfaction with the distribution system and delivery time per country and distribution system in France, Germany, the Netherlands, Spain, the UK, 2011 [Source: Authors' own calculation based on questionnaire data 2011]

* Due to the fact that no wholesaler in the UK stocks all medicinal products the results related to pharmaceutical full-line and short-line wholesalers

have been pooled together and collectively assessed as 'wholesalers'.

With the introduction of DTP in 2007, experts predicted their concerns about quotas, which currently lead to a lack of supply, lack of availability of medicinal products and stock problems. As a consequence, pharmacists are more and more unable to meet the patients' needs and to provide good service $[4,5]$.

As the Netherlands is - compared to its neighbour countries - a low-price country with a high amount of exports, an increasing problem of out of stocks (availability of medicinal products) occurs $[4,19]$.

In Spain, pharmacists complained about shortages of medicinal products and as a result about supply problems when ordering products via direct sales from manufacturers as well as long delivery times. Therefore, pharmacists face problems to provide service for patients as usual [4]. Pharmacists in Germany criticized order conditions offered by direct sales from manufacturers. Generally, pharmacists complained about the decrease in discount rates. $13 \%$ of the pharmacists believe that these decreased discounts would lead to financial problems. The reason may lie in the recent reforms of the healthcare system (GKV-ÄndG, AMNOG, GMG) $[4,20,21]$.

\section{Delivery time}

In order to use medicinal products for therapy, it is necessary that they are available in time. According to the pharmacists' questionnaire findings, the delivery time of the different distribution systems shows the following picture:

- On average, a pharmaceutical full-line wholesaler supplies a pharmacy within a delivery time of 4.53 hours (country specific results: France $=4.80$ hours; Germany $=2.85$ hours; the Netherlands = 16.35 hours; Spain $=4.15$ hours; the UK $=5.70$ hours).

- Pharmacists are supplied within an average delivery time of 14.57 hours by their pharmaceutical short-line wholesaler (country specific results: Germany $=15.90$ hours; the Netherlands $=21.50$ hours).

- Manufacturers (direct sales) distribute their medicinal products within a delivery time of 53.41 hours (country specific results: France $=41.67$ hours; Germany $=26.00$ hours; the Netherlands $=32.55$ hours; Spain $=97.63$ hours; the UK = 48.57 hours).

- In the UK an average pharmacy is supplied within 11.56 hours by RWA, respectively within 17.57 hours by DTP [4]. 
These figures represent the collected and the weighted data respectively from the pharmacists' questionnaires. The reason why the reported delivery time of the pharmaceutical full-line wholesalers (2.66 hours) differs from the perceived one from pharmacists (4.53 hours) is the fact that the night-time, as well as Sundays, were excluded from the reported delivery time [4].

\section{Impact on process costs}

The average individual process steps in pharmacies include determining of order demand, transmission of order, receiving and storage of delivery, checking the delivery note, and invoice $[7,13]$. Based on these findings and on the results from the questionnaires, the process costs as well as the impact on process costs were calculated. On a weighted average, pharmaceutical full-line wholesalers are pooling products of 18.28 manufacturers per delivery. The cost difference of one delivery from a manufacturer is $€ 3.38$ compared to one delivery from one pharmaceutical fullline wholesaler, whereas the cost difference based on 18.28 deliveries from different manufacturers is $€ 199.71$, compared to one delivery from a pharmaceutical full-line wholesaler, where products of 18.28 manufacturers are bundled. According to the reported deliveries per week of the GIRP member organization, pharmacies are supplied on average 15.88 times per week, including deliveries to rural areas. Taking the average deliveries per week into account, the process costs accruing to pharmacies reveal that without pooling, the cost will increase from $€ 6,587.63$ to $€$ $42,877.51$ per year, resulting in a cost difference of $€ 36,289.88$, if $25 \%$ of wholesale deliveries/week were delivered by the manufacturers directly. Direct distribution with weekly deliveries amounting to $50 \%$ of wholesale deliveries would increase the process costs by $€ 79,167.40$ per year. Strictly speaking, with the same delivery frequency, the process costs would increase by $€ 164,922.43$ to $€ 171,510.06$ per year, if there were no pharmaceutical full-line wholesalers.

Table III shows the results of the impact on process costs per pharmacy, country and year. If the pharmacy is supplied only by wholesalers, the process costs per year are the highest with $€ 8,049.71$ in Germany, compared to the Netherlands with $€ 2,670.94$. Without pooling, the costs are highest in Spain with $€ 61,657.62$ and lowest in the Netherlands with $€ 13,780.25$, if $25 \%$ of wholesale deliveries per week are delivered by the manufacturers directly. Direct distribution with weekly deliveries amounting to $50 \%$ of wholesale deliveries, result in process costs of $€$ $123,315.25$ in Spain and of $€ 27,560.50$ in the Netherlands. Assuming the same delivery frequency, the process costs are the highest in Spain with $€ 246,630.49$ and lowest in the Netherlands with $€ 55,121.01$, if there were no pharmaceutical full-line wholesalers. These additional costs would have to be paid by manufacturers, pharmacies and finally by the patients

Currently, the pharmaceutical sector is torn between rapid and radical transformations, such as austerity measures, price decreases, margin cuts and the rise of new alternative distribution models taking place. However, for the pharmaceutical industry and pharmacies and indirectly for patients, the pharmaceutical wholesale sector has proven to be a reliable partner. Additionally, pharmaceutical full-line wholesalers have proven to be vital and reliable partners for policy makers, trying to find strategies and solutions for the current and future challenges in the European health care sector together with policy makers, all other stakeholders involved, the representatives of health funds, and patients [14].

\begin{tabular}{|c|c|c|c|c|}
\hline & $\begin{array}{c}\text { Wholesale deliveries } \\
\text { ( 16 deliveries/week) } \\
(€)\end{array}$ & $\begin{array}{c}\text { Manufacturers } \\
\text { amounting to } 25 \% \text { of } \\
\text { wholesale deliveries } \\
\text { (€) }\end{array}$ & $\begin{array}{l}\text { Manufacturers } \\
\text { amounting to } 50 \% \text { of } \\
\text { wholesale deliveries } \\
(€)\end{array}$ & $\begin{array}{c}\text { Manufacturers } \\
\text { amounting to } 100 \% \text { of } \\
\text { wholesale deliveries } \\
(€)\end{array}$ \\
\hline France & $4,430.36$ & $21,343.27$ & $42,686.53$ & $85,373.06$ \\
\hline Germany & $8,049.71$ & $52,795.11$ & $105,590.23$ & $211,180.46$ \\
\hline Italy & $8,022.95$ & $57,133.12$ & $114,266.23$ & $228,532.47$ \\
\hline The Netherlands & $2,670.94$ & $13,780.25$ & $27,560.50$ & $55,121.01$ \\
\hline Spain & $7,428.83$ & $61,657.62$ & $123,315.25$ & $246,630.49$ \\
\hline The UK & $5,107.58$ & $29,115.92$ & $58,231.83$ & $116,463.67$ \\
\hline Weighted average & $6,587.63$ & $42,877.51$ & $85,755.03$ & $171,510.06$ \\
\hline
\end{tabular}

Table III. Scenario: Impact on process costs per pharmacy and year (pharmaceutical full-line wholesalers vs. direct sales from manufacturers) in France, Germany, Italy, the Netherlands, Spain, the UK, 2011 [Source: Authors' own calculation based on Bureau of Labor Statistics 2010, Center for Healthcare supply chain research 2007, De Grip et al. [8], Instituto Nacional de Estadistica 2008, Istat 2009, pharmacists questionnaire, OECD 2008, Statistisches Bundesamt Deutschland 2010] 


\section{DISCUSSION}

This study, in our knowledge the first providing a systematic overview on the impact of different distribution systems on the access to pharmaceutical products in the key European markets, showed that the pharmaceutical full-line wholesalers have an important and unique position in the pharmaceutical supply chain. In the observed countries alone, pharmaceutical full-line wholesalers prefinance on average $€ 10.2$ bn over a period of 41 days. Moreover, they guarantee the continuous supply of all medicinal products. With the delivery frequency (15.88 times per week), the process costs would increase by $€$ $164,922.43$ to $€ 171,510.06$ per year, if there were no pharmaceutical full-line wholesalers. These findings could be attributed to the consolidated view of the satisfaction of the pharmacists in the observed countries, indicating that pharmacists are very satisfied with the distribution through their pharmaceutical full-line wholesalers.

This study has the following limitations: calculations on the impact of process costs build up on the assumption that each manufacturer distribute to each pharmacy, leading to a very high number of transactions. In the case, if more and more manufacturers would start to deliver directly, some sort of bundling institution (wholesaler or logistics service provider) would establish. Therefore, it is really difficult to compare today's wholesale system with a (theoretical) pure direct delivery scheme, as a pure direct delivery system most probably cannot exist. Moreover, it has to be considered that the findings of the pharmacists' survey are a snap shot of the individual's opinion at a particular moment in time. In addition, the results illustrate a trend.

Other distributors, such as short-line wholesalers or manufacturers through direct sales, carry only a limited product range (their own products) of mostly fast turning, high margin lines and typically do not offer added value services to their customers. Nevertheless, by generating information, direct sales from manufacturers have gained momentum in recent years.
The share of innovative medicinal products of the product portfolio is decreasing, due to the expiration of patents of blockbuster medicinal products. This fact leads to a degression of margins and in the long run to higher prices for patients (e.g. fee for service). The study has proven that other forms of distribution lead to higher costs, would have to be paid by manufacturers, pharmacies and finally by patients.

If pharmaceutical full-line wholesalers cease to exist, the continuous supply of all medicinal products from one single source and in the shortest possible time would no longer be guaranteed. Additionally, without the services provided by pharmaceutical wholesalers that create added value for their customers, they would not be able to focus exclusively on their core business (pharmaceutical manufacturers on the development, production and marketing of medicinal products; pharmacies on the dispensing of medicines and to advice patients; doctors on diagnosing and prescribing therapies to their patients).

Against this background, it can be assumed that pharmaceutical full-line wholesalers will also be engaged more and more in the role of health service providers, which is already the case in the UK and in the Netherlands, where they have become partners of Health Service Centres.

In conclusion, the present study showed that no other distribution model is in the position to keep up with pharmaceutical full-line wholesalers, because they help to reduce transaction costs and secure a safe, rapid and continuous supply of medicinal products. Moreover, they help generate value along the pharmaceutical supply chain by providing complementary services to their supply chain partners.

\section{ACKNOWLEDGEMENTS}

Funding was provided by GIRP (The European Association of Pharmaceutical Full-line Wholesalers - Groupement International de la Répartition Pharmaceutique). The authors would like to thank GIRP and their member organizations for the information provided and their comments. 


\section{REFERENCES}

1. Bünte M, Erhardt M, Sawaya O. Getting to grips with the supply chain, how pharmaceutical companies can enhance patient safety and protect revenues by increasing their control of drug distribution. Booz Allen Hamilton, 2007. Available at:http://www.booz.com/media/uploads/GettingtoGripswiththeSupplyChain.pdf [last accessed February 2012]

2. The European Association of Pharmaceutical full-line Wholesalers (GIRP). Statistic data [database], 2007-2010

3. Office of fair trading (OFT). Medicines distribution, an OFT market study. UK: OFT, 2007. Available at: http:// www.oft.gov.uk/shared_oft/reports/comp_policy/oft967.pdf [last accessed February 2012]

4. Walter E, Dragosits A, Said M. Distribution profile and efficiency of the European pharmaceutical full-line wholesaling sector. Vienna: Institute for Pharmaeconomic Research, 2012

5. Pharmaceutical Services Negotiating Committee (PSNC). The Pharmaceutical Services Negotiating Committee's Response to OFT market study, distribution of medicines in the UK. Buckinghamshire: PSNC, 2007

6. Hofmann E, Maucher D, Richter P, et al. Ways out of the working capital trap, empowering self-financing growth through modern supply management. Berlin: Springer Verlag, 2011

7. Wilke T, Neumann K. Großhandel, Überweisergeschäft oder Direkteinkauf. DAZ 2007; 147: 54-66

8. De Grip A, Sieben I. The Effects of Human Resource Management on Workers' Wage and Firm Productivity. Maastricht: Research Center for Education and the Labour Market, 2003

9. Instituto nacional de estadistica. Annual Wage Structure Survey. Statistical Annex, Year 2008

10. NHS careers, Pay for doctors, healthcare scientists [NHS careers web site]. http://www.nhscareers.nhs.uk [last accessed February 2012]

11. Statistisches Bundesamt Deutschland [database online]. Available at: http://www.destatis.de/jetspeed/portal/cms Sites/destatis/Internet/DE/Content/Statistiken/VerdiensteArbeitskosten/Tarifverdienste/TDB/TDB/Tarifdatenbank [F,templateId=renderPrint.psml] [last accessed February 2012]

12. WK PHARMA [WK-PHARMA website] Available at: www.wk-pharma.fn [last accessed February 2012]

13. Institut für Handelsforschung (IfH). Profil und Effizienz des vollversorgenden pharmazeutischen Großhandels. Köln: Institut für Handelsforschung, 2008

14. Clement W, Walter E, Tuma M. The European Pharmaceutical Wholesale Industry, Structure, Trends, and socioeconomic Importance. Vienna, 2005

15. The European Association of Pharmaceutical full-line Wholesalers (GIRP). Impact of selective distribution arrangements. [Position paper] Brussels: GIRP, 2011

16. The European Association of Pharmaceutical full-line Wholesalers (GIRP). GIRP response to the public consultation in preparation of a legal proposal to combat counterfeit medicines for human use, key ideas for better protection of patients against the risk of counterfeit medicines. Brussels: GIRP, 2008. Available at: http://ec.europa.eu/health/ files/counterf_par_trade/doc_publ_consult_200803/85_european_association_of_pharmaceutical_full_line_wholesalers_en.pdf [last accessed February 2012]

17. EUROSTAT, Population on 1 January by age and sex [database online]. Available online: http://epp.eurostat. ec.europa.eu/portal/page/portal/eurostat/home/ [last accessed February 2012]

18. The European Association of Pharmaceutical full-line Wholesalers (GIRP). The Role of Pharmaceutical Full-line Wholesalers in Europe [Position paper]. Brussels: GIRP, 2009

19. Österreichische Apothekerkammer: Apotheke in Zahlen. Vienna: Österreichische Apothekerkammer, 2011

20. Groth A, Neumann K, Wilke T. GKV-Änderungsgesetz, AMNOG und die Rendite, Ökonomische Auswirkungen und Optionen der betroffenen Apotheken. DAZ 2011; 151: 56-61

21. Thormann P, Lange K. Der pharmazeutische Großhandel, fit für einen veränderten Markt, die kontinuierliche Entwicklung des Geschäftsmodells erlaubt es dem pharmazeutischen Großhandel, auch in Zukunft die Arzneimitteldistribution zum Wohl aller professionell und effizient zu gewährleisten. Germany: Deloitte Consulting, 2007 